\title{
Impact of reed harvesting and Smooth Cordgrass Spartina alterniflora invasion on nesting Reed Parrotbill Paradoxornis heudei
}

\author{
ANTHONY BOULORD, TIAN-HOU WANG, XIAO-MING WANG and \\ GUO-XIAN SONG
}

\begin{abstract}
Summary
The Reed Parrotbill Paradoxornis heudei is an endemic reedbed-inhabiting passerine of east Asia. In the Shanghai municipality, which harbours significant populations of this species, almost all reedbed surfaces are annually harvested. Furthermore, the reedbeds are being invaded by Smooth Cordgrass Spartina alterniflora, an introduced species that can outcompete the native Common Reed Phragmites australis. In this paper, we have shown that Reed Parrotbills do not nest in areas dominated by Smooth Cordgrass and avoid using them. In the areas that are primarily composed of Common Reed, the densities of birds are higher in the unharvested sections. The birds appear to select nesting sites with low Smooth Cordgrass densities, tall reed stems, and relatively equal densities of both dry and green stems. Reed harvesting activity results in vegetation that is too low for bird nesting. However, no nests were found in areas where the reeds had not been harvested for several years and had high densities of dry reed stems; these results could be attributed to the fact that the high density of broken stems reduced the vegetation cover. On the basis of our results, we recommend implementation of four years harvesting-cycle rotation and avoidance of reclamation in reedbeds which have not been invaded by Smooth Cordgrass.
\end{abstract}

\section{Introduction}

The Reed Parrotbill Paradoxornis heudei David, 1872 is a reedbed-inhabiting passerine distributed in China, Mongolia, and Russia (BirdLife International 2008) and, because of habitat loss, this species is currently listed as 'Near Threatened'. However, these threats have not been clearly defined (BirdLife International 2008), and more relevant ecological knowledge is required to enhance the management of reedbeds and promote the conservation of this species.

Reed Parrotbills are found in the Shanghai municipality. Since there are no clearly defined measures for reedbed management in this region, almost all the reedbed areas are harvested by local farmers during the period between November-December and April. This practice can have a negative impact on reed-inhabiting arthropods (Schmidt et al. 2005) and bird communities (Poulin and Lefebvre 2002). Graveland (1999) showed that the densities and breeding success of some reedbed-nesting passerines were greater in unharvested areas, in comparison with the corresponding values in harvested areas. Therefore, we hypothesized that reed harvesting would have a negative impact on Reed Parrotbills. Another potential threat for this species is a reduction in the area of suitable habitat due to invasion by Smooth Cordgrass Spartina alterniflora. Smooth Cordgrass shows various properties relevant to ecological engineering, such as a great capacity for mitigating erosion and trapping sediments. This species has been deliberately introduced into coastal and estuarine regions of China and is currently flourishing in 
the region from Guangxi to Tianjin (Chen et al. 2004, Chung 2006). Owing to its stronger reproductive capacity and wider ecological niche, Smooth Cordgrass has rapidly expanded and outcompeted the native species ( $\mathrm{Li}$ and Zhang 2007) and is currently found in monospecific patches that were previously occupied by native species such as Common Reed Phragmites australis. In 1985, the coverage of Smooth Cordgrass in six Chinese counties was approximately 260 ha (Chung 1989), and by 2000 this had increased to more than 112,000 ha (An et al. 2007). Observations during winter indicated that Reed Parrotbills are present in areas covered by Common Reed, and the birds avoid Smooth Cordgrass (Ma et al. 2007). Therefore, we also hypothesize that Smooth Cordgrass expansion is a serious threat for Reed Parrotbill because of large-scale habitat losses.

In 2007, we conducted a study on Reed Parrotbills to determine the impact of both annual reed harvesting and Smooth Cordgrass distribution on the individual densities of birds during the nesting period. We used two methods (individual observations and nest-detection based estimates) and compared the results to estimate bird densities. We also analyzed the reedbed vegetation cover to define the vegetation requirements for nesting Reed Parrotbills.

\section{Methods}

\section{Study areas}

The study was conducted in the Chongming Dongtan National Nature Reserve $\left(121^{\circ} 5 \mathrm{O}^{\prime}-\right.$ $122^{\circ} 5^{\prime} \mathrm{E} 31^{\circ} 25^{\prime}-31^{\circ} 38^{\prime} \mathrm{N}$ ), which is a complex of coastal wetland ecosystems listed as a Ramsar Wetland of International Importance. The reserve is situated on the eastern end of the Chongming Island in the Yangtze Estuary and constitutes the largest wetland area in the Shanghai municipality.

We selected two 4.5 ha $(300 \mathrm{~m} \times 150 \mathrm{~m})$ sample areas located in the reedbed of the reserve, namely, the harvested and non-harvested areas (Figure 1 ). In the harvested area, the reeds were harvested annually and in the non-harvested area, the reeds had not been harvested since 2004 . The reedbed contained three major types of vegetation cover arising from different invasion stages: monospecific stands of Common Reed, mixed areas with Common Reed and Smooth

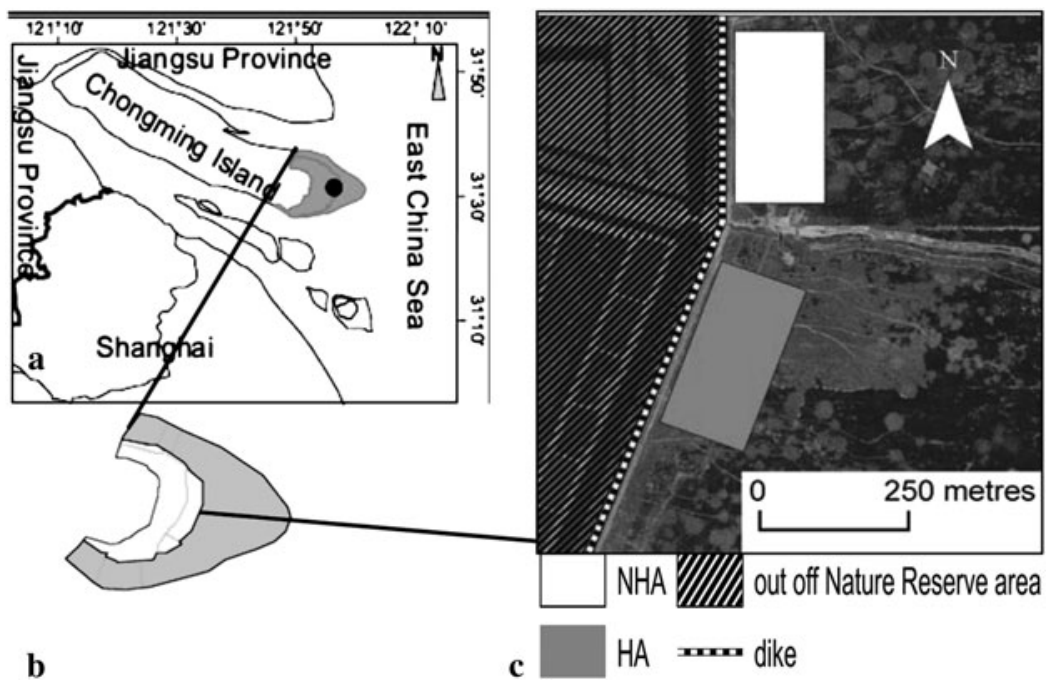

Figure 1. (a) Location of Chongming Island, (b) Chongming Dongtan Nature Reserve (grey area on part b), and (c) the non-harvested (NHA) and harvested (HA) reedbed sample areas. 
Cordgrass, and monospecific stands of Smooth Cordgrass. As it was difficult to distinguish the exact boundaries between monospecific stands of Common Reed and mixed areas, we pooled them together to finally define two types of vegetation cover (Table $I$ and Figure 2).

\section{Habitat use and selection}

We determined the bird abundance in each sample area using counts of both nests and individual birds.

Nest counts. Nest searches were undertaken between May and July. We identified nests by systematically searching through the reeds, which were divided into $3 \mathrm{~m}$ wide transects covering the entire sample area, every two weeks (a total of three investigations were performed for each sample area). To determine the number of individuals in each habitat, we considered that each nest was occupied by two individuals.

Individual counts. The individual numbers were directly determined by using a point-transect method conducted between 20 June and I August. The counts $(n=5$ in each sample area) were made at intervals of $10 \pm 2.6$ days. In each sample area, six 0.5 ha sites $(50 \mathrm{~m} \times 150 \mathrm{~m})$ were delimited and observed from the dike during to minute observation periods using binoculars. Only individuals perched on vegetation were counted and the habitat type for each observation noted as mixed reed/cordgrass or monospecific cordgrass. All observations were made by the same observer from o6hoo to Iohoo on days when there was no rain and little wind.

A chi-square goodness-of-fit test was used to identify whether there was any significant association between the presence of nests and any particular habitat (Neu et al. 1974). We did not perform a chi-square test with the individual counts, because the expected frequencies were not higher than 5, which is a prerequisite for performing this test (Cochran 1952). Since we did not count any individuals in the Smooth Cordgrass patches, we used a Student's t-test to compare the means of individuals in harvested and non-harvested areas.

\section{Vegetation sampling}

In each sample area, we defined two $300 \mathrm{~m}$ parallel transects that were separated by a width of $50 \mathrm{~m}$. Then, $50 \mathrm{~cm} \times 50 \mathrm{~cm}$ quadrats were installed at $50 \mathrm{~m}$ intervals along each transect (14 quadrats in each sample area). Between 23 May and 15 June, we measured the number, height, and diameter of both dry and green reed and cordgrass stems.

Since reed growth occurring between 23 May and 15 June could have had an impact on the results, we estimated the bias due to reed growth and obtained two measurements of green reed stems in the harvested area quadrats (22-23 May and 13-15 June). We compared the mean heights in the two quadrat sets by using an independent-sample 2-tailed Student's t-test. The total mean of the green stem heights on the harvested area was $67.1 \pm 18.8 \mathrm{~cm}(n=11)$ in May and $71.8 \pm 20.1 \mathrm{~cm}(n=11)$ in June. The height difference was not significant $\left(t\right.$ test; $t_{20}=$ $-0.57 ; P=0.57$ ), suggesting that the differences between quadrats cannot be explained by reed growth during the study period. For comparison with other areas, we used data obtained in the month of June for the harvested area.

Between 1o May and 24 June, these measurements were also performed on quadrats installed around the 13 nests built during that period. We analyzed all the nest sites discovered on the

Table 1 . Vegetation covers of the reedbed study areas (ha).

\begin{tabular}{llll}
\hline Vegetation cover & Non-harvested area & Harvested area & Total \\
\hline Mixed reed/cordgrass & $3.69(82 \%)$ & $3.74(83 \%)$ & $7.43(83 \%)$ \\
Monospecific cordgrass & $0.81(18 \%)$ & $0.76(17 \%)$ & $1.57(17 \%)$ \\
Total & 4.5 & 4.5 & 9 ha \\
\hline
\end{tabular}




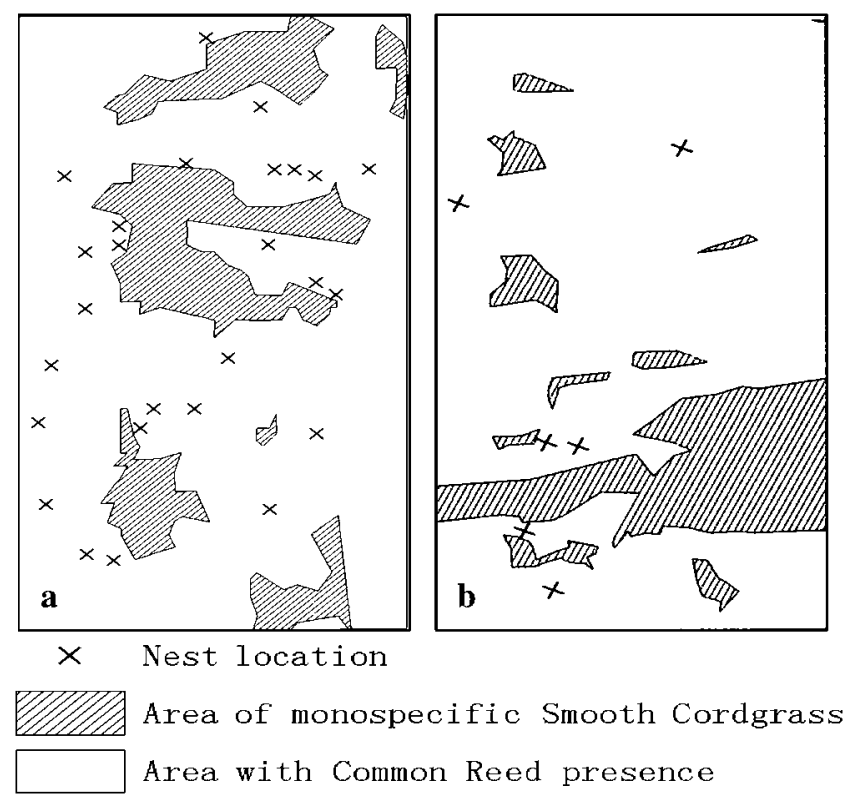

Figure 2. Locations of monospecific Smooth Cordgrass stands, mixed areas of Common Reed and Smooth Cordgrass and Reed Parrotbill nests in the (a) non-harvested and (b) harvested sample areas.

harvested area during this period $(n=3)$ and the 1o nest sites found on the non-harvested area. This group of nests and the surrounding quadrats were defined as the NEST group $(n=13$ in total). For each vegetation-structure parameter, we used 1-way analysis of variance (ANOVA) to test the significant differences among groups (harvested, nonharvested, and NEST). Normal distributions were examined by a Q-Q plot graphical method, which showed that all the data were normally distributed. When the results of Levene's test showed homogenous variances, significant differences between groups were analyzed using a Tukey HSD posthoc test. In the cases of non-homogenous variances, a Games-Howell test was used. We used principal component analysis (PCA) to define the principal vegetation factors impacting Reed Parrotbill nest-site selection. In PCA, we used measurements of the previously described vegetation components on each of the 41 quadrats, namely, the harvested $(n=14)$, nonharvested $(n=14)$, and NEST $(n=13)$ quadrats. After projection of each quadrat on the chosen axis, we determined by eyes the number and characteristics of vegetation categories revealed with PCA analysis.

All statistical analyses and graphs were performed using SPSS 13.0 software. Maps were created using ArcGis 9.o Service Pack 3. The significance level for all tests was maintained at $P<0.05$. The mean values were presented along with the standard deviation (SD) values, unless otherwise stated.

\section{Results}

\section{Habitat use and selection}

Using the nest-count method, individuals were not uniformly distributed among the habitats and we estimated that 12 individuals had nested in the harvested area and 52 individuals had nested in non-harvested area (Table 2 and Figure $2, \chi^{2}{ }_{3}=44.5 ; P<$ o.001). Fewer birds then expected were 
observed in the harvested area (both habitats) and in the monospecific stands of Smooth Cordgrass in the non-harvested area.

The mean of the individual counts in areas with the presence of the Phragmites in the harvested area $(4.0 \pm 1.6 ; n=5)$ was significantly lower than that in non-harvested (11.8 \pm 3.5 ; $n=5)$ ( $t$ test; $\left.t_{8}=4.55 ; P=0.002\right)$. No individual was observed perching in monospecific patches of Smooth Cordgrass in either area, and no nests were found within these patches.

\section{Vegetation structure}

There were no significant inter-quadrat differences in green reed density (ANOVA; $F_{2,37}=2.59$; $P=0.09$ ), green reed diameter (ANOVA; $F_{2,33}=1.28 ; P=0.29$ ), and green Smooth Cordgrass density (ANOVA; $F_{2,37}=2.72 ; P=0.08$ ). However, the non-harvested quadrats had the lowest green reed densities, and the nest quadrats had the lowest green Smooth Cordgrass densities. The high standard deviations reflect high heterogeneities for both green reed and green cordgrass densities, probably explaining the absence of many significant differences. The green reed heights, dry reed heights, densities, and diameters varied between the quadrat types (ANOVA, respectively $F_{2,33}=10.89, P<$ o.001; $F_{2,24}=9.14, P=0.001 ; F_{2,37}=13.43, P<$ 0.001; $\left.F_{2,24}=4.09, P<0.03\right)$. The green reed heights, dry reed heights, densities and diameters for the nest and non-harvested area quadrats were found to be statistically similar. However, the green reed heights, dry reed heights, and densities in the harvested area quadrats were significantly lower than the corresponding values in the nest quadrats (Figure 3). The dry Smooth Cordgrass densities varied between areas (ANOVA; $F_{2,37}=7.16 ; P=0.002$ ), and were significantly higher on the non-harvested quadrats than on the nest harvested quadrats. We did not detect any significant differences between the dry smooth cordgrass densities in the nest and harvested groups (Figure 3).

The Common Reed densities for both green and dry stems on all nest and non-nesting nonharvested area quadrats were similar, and these reed densities differed from the vegetation components in non-nesting harvested areas which had high green stem and low dry stem densities. Reed heights of both green and dry stems were significantly related to nest presence. These nests tended to be located in the areas containing the highest stems.

\section{PCA on the vegetation requirements for nesting}

The PCA analysis revealed two principal components with eigenvalues greater than 1 . The analysis explained $76 \%$ of the variation in the vegetation data, i.e., $51 \%$ and $25 \%$ on axes 1 and 2 , respectively (Table 3 ). The height and diameter of both green and dry reed stems were strongly positively correlated with the first component; in contrast, dry reed stem density also lesser positive influence and green reed stem density was not significantly associated with the first

Table 2. Number of Reed Parrotbill nests observed and predicted to be present in the available habitats according a uniform nest distribution.

\begin{tabular}{llr}
\hline Habitat & Number of nests & Expected \\
\cline { 3 - 3 } & Observed & 26.6 \\
\hline Harvested Area & & 5.4 \\
Mixed reed/cordgrass & 12 & 26.2 \\
Monospecific cordgrass & 0 & 5.8 \\
Non-harvested Area & 52 & 0 \\
Mixed reed/cordgrass & 5 & 0 \\
Monospecific cordgrass & &
\end{tabular}


Green stems of Common Reed
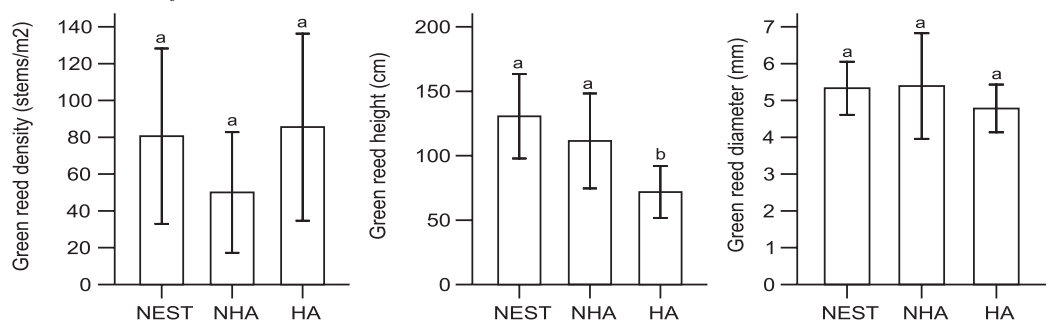

Dry stems of Common Reed
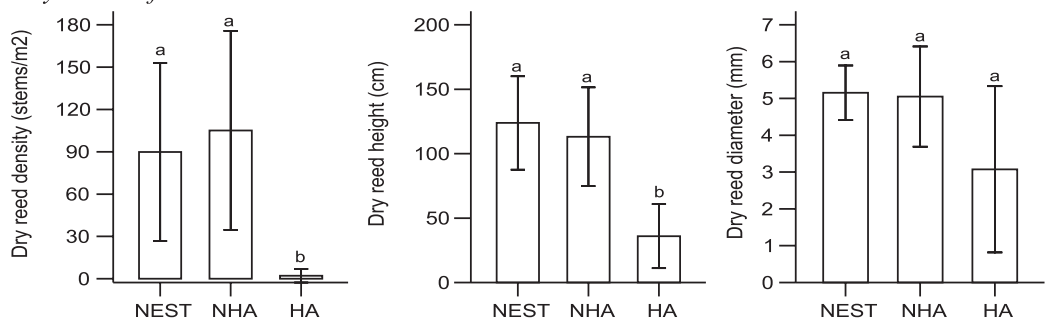

Smooth Cordgrass
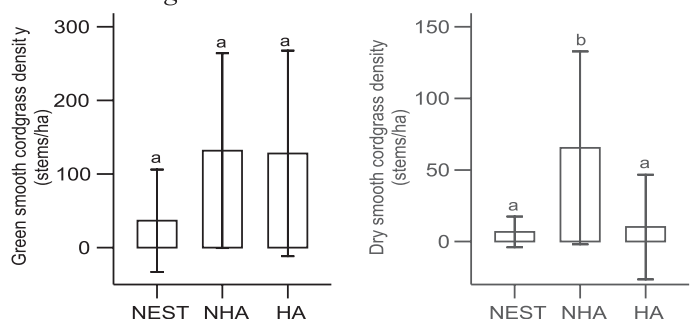

Figure 3. Vegetation structure surrounding nests (NEST), nonharvesting (NHA) and harvesting (HA) areas. The letters $a$ and $b$ denote significant differences between areas (Tukey HSD or Games-Howell test, significance level: $P<0.05)$. Error bars represent the standard deviations.

component. The density of green cordgrass density was negatively associated with the first component. The first axis was therefore defined by both the vegetation type and the height and diameter of the reeds. The dry stem densities of both Common Reed and Smooth Cordgrass were strongly positively correlated with the second component. In contrast, green reed stem density was negatively correlated with this component. Therefore, this axis represented the maturity level of the reedbed.

Quadrats situated low on the first axis tended to have a vegetation structure with high Smooth Cordgrass density and low reed height and diameter. Quadrats situated high on the first axis tended to have low Smooth Cordgrass density and high reed height and diameter. For the second axis, a high score reflected an aged vegetation structure with high densities of dry stems and low densities of green stems, while low scores reflected a young vegetation structure with high densities of green reed stems and low densities of dry stems (Figure 4).

We observed four categories in the projection of reedbed vegetation quadrat (Figure 4). The first category contained quadrats with high Smooth Cordgrass densities with practically no Common Reed. Both harvested and non-harvested areas contained areas with this type of vegetation cover, but no nesting quadrats were identified within this vegetation category. Thus, 
Table 3. Results of Principal Components Analysis showing the first 3 axes of vegetation structure.

\begin{tabular}{lcrr}
\hline Variable points & \multicolumn{2}{l}{ Axis } & \\
\cline { 2 - 4 } & \multicolumn{1}{l}{ I } & 2 & 3 \\
\hline Green reed density & 0.06 & -0.69 & 0.70 \\
Green reed height & 0.92 & -0.02 & 0.07 \\
Green reed diameter & 0.84 & -0.34 & 0.12 \\
Dry reed density & 0.55 & 0.66 & 0.26 \\
Dry reed height & 0.88 & 0.39 & -0.05 \\
Dry reed diameter & 0.84 & 0.33 & 0.06 \\
Green Smooth Cordgrass density & -0.70 & 0.41 & 0.32 \\
Dry Smooth Cordgrass density & -0.47 & 0.75 & 0.29 \\
Eigenvalues & 4.1 & 2.0 & 0.8 \\
Percentage of variance & 50.8 & 25.2 & 9.5 \\
Total percentage & 50.8 & 76.0 & 85.5 \\
\hline
\end{tabular}

although areas with high Smooth Cordgrass densities were observed, no nests were found to be built in these areas.

The second category contained non-harvested areas quadrats with the oldest vegetation structures. These quadrats had the highest densities of dry stems and the lowest densities of green stems. There were no nesting quadrats in this vegetation category, indicating that the nests were not present in the oldest reed growth areas.

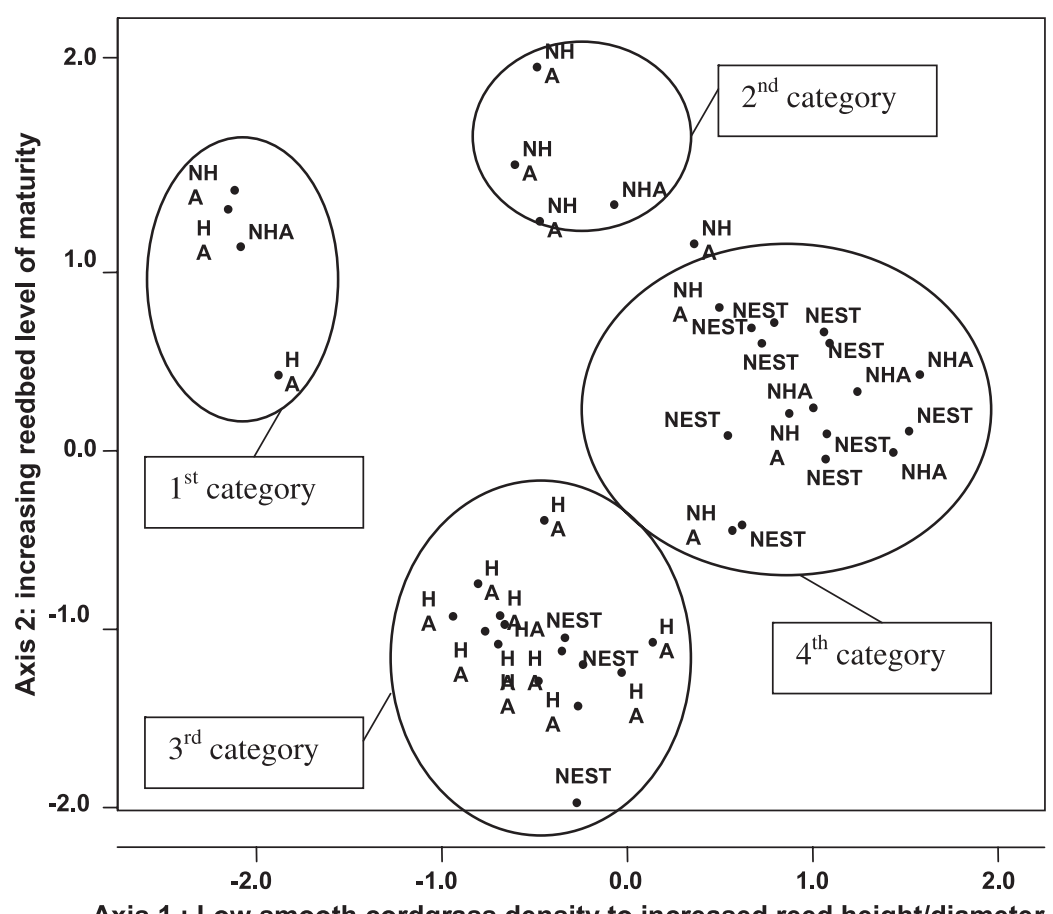

Axis 1 : Low smooth cordgrass density to increased reed height/diameter

Figure 4. Projection of reedbed-vegetation quadrat data (NEST, quadrats surrounding nests; HA, quadrats on harvested area; NHA, quadrats on non-harvested area) on the 2 first axes of PCA. 
The third category contained quadrats where the vegetation was youngest with highest densities of green reed stems and lowest densities of dry stems. This category included quadrats from the harvested area, none from the non-harvested area and three of the 13 identified nesting quadrats.

The fourth category contained quadrats where reed stems were tallest and the Smooth Cordgrass densities were lowest, in comparison with the corresponding values for the other categories. These quadrats also had relatively equal densities of dry and green stems. This last category, which was present only on the non-harvested area samples, contained 10 of the 13 nests found in the study.

\section{Annual impact of reed harvesting}

Counts of both nests and individual birds showed that adult densities in annually harvested areas were lower than those in non-harvested areas. The most frequently used nesting areas were those with the tallest reed stems and where the densities of both dry and green reed stems were similar. The results of the study suggest that the vegetation height in harvested areas was too low to provide suitable habitat for bird nesting. Moreover, the lower densities of individuals in the harvested reedbed can be explained by the fact that the quantities of arthropods that constitute potential food sources for Reed Parrotbills seem to be lower in harvested areas (Xiong et al. 2007). It can be suggested that a no-harvesting approach, which will create older areas with high drystem densities, may be suitable for bird nesting. However, our study did not support such a hypothesis. We found that the Reed Parrotbills avoided the oldest stem regions while nesting and this behaviour can be attributed to the fact that the stems of both old and young reeds at these sites were too low for nesting. If unharvested, reed stems remain intact for 2-3 years and gradually break up (Haslam 1972, Hawke and Jose 1996). Consequently, in areas with a high density of dry stems, the reed stems have a low mean height. Since the green stem densities on unharvested areas are lower than those in harvested areas, the low mean height of reed stems cannot be compensated for by green stem heights.

It appears that reed height strongly influences the nesting of the Reed Parrotbill, as has been observed for Acrocephalus warblers by Leisler et al. (1989). Areas harvested annually do not provide suitable nesting habitats due to the low reed height and probably the almost complete absence of dry stems. However, in our opinion, the study indicates that some reed harvesting is necessary to provide young reedbeds and maintain an appropriate balance between densities of green and dry stems and a suitable vegetation height, a combination that is strongly preferred by the species for nesting.

\section{Impact of Smooth Cordgrass invasion}

Several studies have shown that Smooth Cordgrass invasion altered the structure of the trophic functional groups of benthic nematode communities (Chen et al. 2007) and macroinvertebrates (Chen et al. 2005), reduced the species richness and density of shorebirds by reducing habitat quality (Chen et al. 2007) and reduced the quality of breeding areas of Saunder's Gull (Jiang et al. 2010). Our results complement these studies by showing that Smooth Cordgrass invasion in reedbeds decreases the habitat quality for Reed Parrotbills. The absence of both observed individuals and nests in monospecific Smooth Cordgrass areas indicates that the Reed Parrotbill is strongly dependent on Common Reed. Our results are in accordance with those provided by Gan et al. (2006), who showed the same avoidance of Smooth Cordgrass patches during winter. According to these authors, higher stem densities and biomass values in monospecific patches of Smooth Cordgrass appear to hamper bird movement through stems. Our results also showed that a majority of the nests were built in taller vegetation patches. In mixed areas, the tallest reed stems were localized in areas with the lowest Smooth Cordgrass densities, probably because in 
mixed areas Smooth Cordgrass alters the growth of the Common Reed. Consequently, the vegetation cover for nesting is extremely low. Thus, it is likely that the rapid expansion of Smooth Cordgrass in reedbeds in Chongming Dongtan Nature Reserve and generally in the Shanghai municipality appears to be a serious threat for Reed Parrotbill habitats and for the survival of the species.

\section{Implications for management}

The Environmental Protection Bureau of China has already listed Smooth Cordgrass as a harmful exotic species. Measures to control this species have drawn significant attention from biologists and ecologists from China and abroad, who have experimented with physical, chemical, biological, and ecological methods (Farber et al. 2002, Fisher et al. 2005, Wang et al. 2008). However, Huang et al. (2007) showed that the expansion rate of Smooth Cordgrass is 3-5 times higher than that of Common Reed and predicted that range expansion of Smooth Cordgrass will continue. The conservation of biodiversity should entail maintenance of genetic diversity (De Salle and Amato 2004), which is presumably correlated with adaptability (Frankham 1995) and survival (Vrijenhoek 1994). In Dongtan, since genetic exchanges with other Reed Parrotbill populations are unknown and probably very low, maintaining a high population size is crucial for avoiding a decrease in genetic diversity. However, in Chongming Dongtan Nature Reserve, the area of Common Reed has fallen by $55 \%$ in the five years since Smooth Cordgrass was introduced (Huang et al. 2007). Thus, Smooth Cordgrass expansion constitutes a real problem for Reed Parrotbill conservation. Outside the nature reserve, reedbeds without Smooth Cordgrass have been identified in fishponds which are being considered for development as a green park. In order to counter habitat disappearance and maintain a viable population size, we recommend that it is necessary to maintain and manage the reedbed habitats in these fishponds until expansion of Smooth Cordgrass in the nature reserve has been stopped.

In order to maintain a balance between maturation and rejuvenation of reedbeds and ensure suitable nesting habitats for the Reed Parrotbill, we also recommend rotational harvesting in the regions inside and outside the nature reserve. This management system can provide heterogeneous habitats that will satisfy the needs of various species and increase the conservation value of reedbed habitats (Poulin and Lefebvre 2002). Furthermore, on unharvested areas, dry stems crack and break, fall to the ground, and constitute a litter layer that needs several years to decompose (Haslam 1972). Litter accumulation leads to reedbed drying, which permits other species to colonize (Haslam 1972) and, over time, litter accumulation results in the loss of suitable habitat for the Reed Parrotbill. Harvesting prevents this natural process by removing litter. Güsewell et al. (2000) indicate that a harvested reedbed reaches a height similar to that of a non-harvested reedbed after the third year. Since dry stems remain 2-3 years after growth, a harvesting-cycle rotation with a duration of four years or less can be considered as best practice.

\section{Acknowledgments}

This study was supported in part by grants from the Technology and Science Ministry Key Project of China during the Eleventh Five-Year Period (No. 2006BACo1A14), the Shanghai Municipal Science and Technology Committee of China (No. 08DZ1203202 and No. 08231200701) and the Project Arcus 2006 Languedoc-Roussillon/China Arcus Chongming Project. Many thanks to members of the Shanghai Key Laboratory of Urbanization and Ecological Restoration of School of Life Sciences, East China Normal University, and particularly Zheng-huan Wang for helping field investigation planning, Xiao-jun Xu and Bin Dong for their assistance with the collection of the field data. We appreciate the improvements in English usage made by Phil Whitford through the Association of Field Ornithologists' programme of editorial assistance. 


\section{References}

An, S. Q., Gu, B. H., Zhou, C. F. Wang, Z. S., Deng, Z. F., Zhi, Y. B., Li, H. L., Chen, L., Yu, D. H. and Liu, Y. H (2007) Spartina invasion in China: implications for invasive species management and future research. Weed Res. 47: 183-191.

BirdLife International (2008) Paradoxornis heudei. In: IUCN 2008. 2008 IUCN Red List of threatened species. www.iucnredlist. org. Downloaded on 3 April 2009

Chen, Z. Y., Li, B., Zhong, Y. and Chen, J. K. (2004) Local competitive effects of introduced Spartina alterniflora on Scirpus mariqueter at Dongtan of Chongming Island, the Yangtze River Estuary and their potential ecological consequences. Hydrobiologia 528: 99-106.

Chen, Z. Y., Fu, C. C., Wang, H. Y., Li, B., Wu, J. H. and Chen, J. K. (2005) Effect of Spartina alterniflora invasions on the benthic macroinvertebrates community at Dongtan of Chongming salt marsh, the Yangtze River Estuary. Wetland Sci. 3: 1-7. Chen, H. L., Li, B., Hu, J. B., Chen, J. K. and $\mathrm{Wu}$, J. H. (2007) Benthic nematodes in the Yangtze River estuary as influenced by Spartina alterniflora invasions. Mar. Ecol. Prog. Ser. 336: 99-110.

Chung, C. H. (1989) Ecological engineering of coastline with salt marsh plantations. Pp. 255-289 in W. J. Mitsch and S. A. Jorgensen, eds. Ecological engineering: an introduction to eco-technology. New York: Wiley.

Chung, C. H. (2006) Forty years of ecological engineering with Spartina plantations in China. Ecol. Eng. 27: 49-57.

Cochran, W. G. (1952) The $\chi^{2}$ test of goodness of fit. Ann. Math. Stat. 23: 315-346.

De Salle, R. and Amato, G. (2004) The expansion of conservation genetics. Nat. Rev. Genet. 5: 702-712.

Farber, S. C., Costanza, R. and Wilson, M. A. (2002) Economic and ecological concepts for valuing ecosystem services. Ecol. Econ. 41: 375-392.

Fisher, A. J., Di Tomaso, J. M. and Gordon, T. R. (2005) Intraspecific groups of Claviceps purpurea associated with grass species in Willapa Bay, Washington, and the pros- pects for biological control of invasive Spartina alterniflora. Biol. Control 34: 170-179.

Frankham, R. (1995) Conservation genetics. Annu. Rev. Genet. 29: 305-327.

Gan, X., Zhang, K., Ma, Z., Chen, J. and Li, B. (2006) The effect of invasions of the grass Spartina alterniflora on wintering birds on Chongming Island, Dongtan Reserve, China. J. Ornithol. 147 (suppl.): 1-169.

Graveland, J. (1999) Effects of reed cutting on density and breeding success of Reed Warbler Acrocephalus scirpacaeus and Sedge Warbler A. schoenobaenus. J. Avian Biol. 30: 469-482.

Güsewell, S., Le Nédic, C. and Buttler, A. (2000) Dynamics of Common Reed (Phragmites australis, Trin.) in Swiss fens with different management. Wetlands Ecol. Manage. 8: 375-389.

Haslam, S. M. (1972) Biological flora of the British Isles: Phragmites communis Trin. J. Ecol. 60: 585-610.

Hawke, W. D. and Jose, P. V. (2006) Reedbed management for commercial and wildlife interests. Sandy, UK: Royal Society for the Protection of Birds.

Huang, H. M., Zhang, L. Q. and Yuan, L. (2007) The spatio-temporal dynamics of salt marsh vegetation for Chongming Dongtan National Nature Reserve, Shanghai. Carcinogeneis, Teratogenesis and Mutagenesis 27: 4166-4172.

Jiang, H. X., Hou, Y. Q., Chu, G. Z., Qian, F. W., Wang, H., Zhang, G. G. and Zheng, G. M. (2010). Breeding population dynamics and habitat transition of Saunders's Gull Larus saundersi in Yancheng National Nature Reserve, China. Bird. Conserv. Intnl. 20: 13-24.

Leisler, B., Ley, H. W. and Winkler, H. (1989) Habitat, behaviour and morphology of Acrocephalus warblers: an integrated analysis. Ornis Scandinavica 20: 181-186.

Li, H. and Zhang, L. (2007) An experimental study on physical controls of an exotic plant Spartina alterniflora in Shanghai, China. Ecol. Eng. 32: 11-21.

Ma, Z. J., Gan, X. J., Choi, C. Y., Jing, K., Tang, S., Li, B. and Chen, J. K. (2007) 
Wintering bird communities in newlyformed wetland in the Yangtze River estuary. Ecol. Res. 22: 115-124.

Neu, C. W., Byers, C. R. and Peek, J. M. (1974) A technique for analysis of utilization-availability data. J. Wildl. Manage. 38 : 541-545.

Poulin, B. and Lefebvre, G. (2002) Effect of winter cutting on the passerine breeding assemblage in French Mediterranean reedbeds. Biodiv. Conserv. 11: 1567-1581.

Schmidt, M. H., Lefebvre, G., Poulin, B. and Tscharntke, T. (2005) Reed cutting affects arthropod communities, potentially reduc- ing food for passerine birds. Biol. Conserv. 121: 157-166.

Vrijenhoek, R. C. (1994) Genetic diversity and fitness in small populations. Pp. 37-53 in V. Loeschcke, J. Tomiuk and S. K. Jain, eds. Conservation Genetics. Basel: Birkhäuser. Wang, G., Qin, P., Wan, S. W., Zhou, W. Z., Zai, X. M. and Yan, D. L. (2008) Ecological control and integral utilization of Spartina alterniflora. Ecol. Eng. 32: 249-255.

Xiong, L. H., Wu, X., Gao, W., Zhou, J. and Liu, J. J. (2007) Impact of reed cutting on foraging of Reed Parrotbill Paradoxornis heudei. Chinese J. Zool. 42: 41-47.

\section{ANTHONY BOULORD, TIAN-HOU WANG*, XIAO-MING WANG}

Shanghai Key Laboratory of Urbanization and Ecological Restoration, School of Life Sciences, East China Normal University, 3663 N Zhongshan Rd, Shanghai, 200o62, P. R. China.

\section{GUO-XIAN SONG}

Chongming Dongtan Nature Reserve, Dongwang Rd, Chongming district, Shanghai, 202182, P.R. China

*Author for correspondence; email: thwang@bio.ecnu.edu.cn

Received 20 November 2008; revision accepted 27 May 2009;

Published online 19 March 2010 